\title{
Perspective - synthetic DEMs: A vital underpinning for the quantitative future of landform analysis?
}

\author{
J. K. Hillier ${ }^{1}$, G. Sofia ${ }^{2}$, and S. J. Conway ${ }^{3, a}$ \\ ${ }^{1}$ Dept. Geography, Loughborough University, Loughborough, LE11 3TU, UK \\ ${ }^{2}$ Dept. Land, Environment, Agriculture and Forestry, University of Padova, Agripolis, \\ viale dell'Università 16, 35020 Legnaro (PD), Italy \\ ${ }^{3}$ Dept. Physical Sciences, The Open University, Milton Keynes, MK7 6AA, UK \\ anow at: Laboratoire de Planétologie et Géodynamique de Nantes, Université de Nantes, 2 rue de la \\ Houssinière, Nantes, 44300 CEDEX 3, France \\ Correspondence to: J. K. Hillier (jkhillier@lboro.ac.uk)
}

Received: 13 July 2015 - Published in Earth Surf. Dynam. Discuss.: 29 July 2015

Revised: 23 November 2015 - Accepted: 3 December 2015 - Published: 16 December 2015

\begin{abstract}
Physical processes, including anthropogenic feedbacks, sculpt planetary surfaces (e.g. Earth's). A fundamental tenet of geomorphology is that the shapes created, when combined with other measurements, can be used to understand those processes. Artificial or synthetic digital elevation models (DEMs) might be vital in progressing further with this endeavour in two ways. First, synthetic DEMs can be built (e.g. by directly using governing equations) to encapsulate the processes, making predictions from theory. A second, arguably underutilised, role is to perform checks on accuracy and robustness that we dub "synthetic tests". Specifically, synthetic DEMs can contain a priori known, idealised morphologies that numerical landscape evolution models, DEM-analysis algorithms, and even manual mapping can be assessed against. Some such tests, for instance examining inaccuracies caused by noise, are moderately commonly employed, whilst others are much less so. Derived morphological properties, including metrics and mapping (manual and automated), are required to establish whether or not conceptual models represent reality well, but at present their quality is typically weakly constrained (e.g. by mapper inter-comparison). Relatively rare examples illustrate how synthetic tests can make strong "absolute" statements about landform detection and quantification; for example, $84 \%$ of valley heads in the real landscape are identified correctly. From our perspective, it is vital to verify such statistics quantifying the properties of landscapes as ultimately this is the link between physics-driven models of processes and morphological observations that allows quantitative hypotheses to be tested. As such the additional rigour possible with this second usage of synthetic DEMs feeds directly into a problem central to the validity of much of geomorphology. Thus, this note introduces synthetic tests and DEMs and then outlines a typology of synthetic DEMs along with their benefits, challenges, and future potential to provide constraints and insights. The aim is to discuss how we best proceed with uncertainty-aware landscape analysis to examine physical processes.
\end{abstract}

\section{Introduction}

Physical processes sculpt planetary surfaces such as the Earth's. A fundamental tenet of geomorphology is that the form of the surface created, when combined with other data or modelling, can be used to understand those processes. This endeavour to reconcile observation and theory is, essentially, model validation (e.g. Martin and Church, 2004;
Pretty, 2009, 2010) summarised by the question "Has the right model been constructed?" (Balci, 1998). Figure 1 illustrates the pathways towards reconciliation between observations of reality and models, which in geomorphology is conducted through some properties or metrics diagnostic of the landscape of interest; the pathways lead to this reckoning from both physical reality and from conceptual models, 


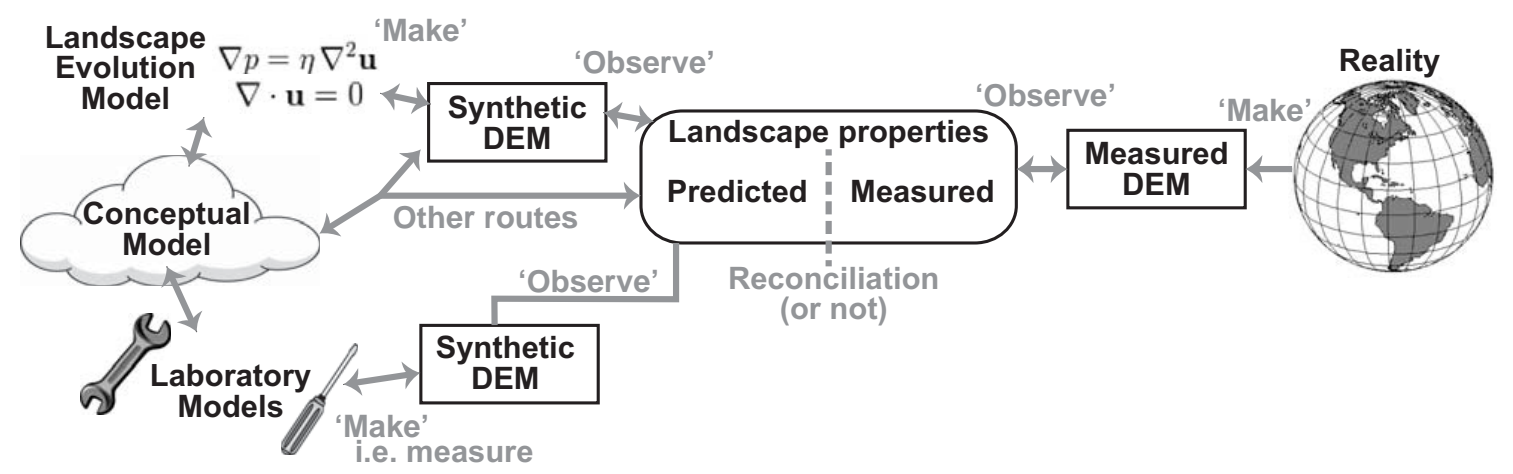

Figure 1. Illustration of the pathways and stages in reconciling geomorphological models with reality in order to understand the physical processes that sculpt planetary surfaces. Stages are in black, and tasks undertaken to move between them are in grey, with double-headed arrows indicating possible feedbacks. Synthetic DEMs may be created through various routes, and may be employed to add rigour to both the making of DEMs and the observing of them to derive landscape properties.

which may vary in sophistication (e.g. may even be qualitative). Whilst visual comparisons of landscape properties are obviously possible, quantitative morphometrics of DEMs ("observe" in Fig. 1) are a stronger approach, and these vary according to the types of study being undertaken.

Discrete landforms (see Evans, 2012) (e.g. craters, cirques, drumlins, volcanoes) can be delimited with a closed boundary and then isolated in order to quantify key characteristics such as height, $H$, or slope of a flank (e.g. Hillier, 2008). Linear features (e.g. rivers) can also be measured. Equally, spatially continuous properties of digital elevation models (DEMs) can be quantified (e.g. roughness, wetness index) (Beven and Kirkby, 1979; Grohmann et al., 2011; Eisank et al., 2014). Such morphology-derived observational data, including metrics from mapping that is both manual and automated, add to the more qualitative assessments that may be drawn directly from geomorphological maps.

Quantifying discrete landforms can give additional insights and provide constraints on models of physical processes. For example, discrete fluvial bedforms and their variability are quantified and used to predict extremes for engineering purposes (e.g. depth to place a pipeline) (van der Mark et al., 2008). Impact crater size-frequency distributions are used to estimate the age of the surface of the Moon and planetary bodies (e.g. Mars and Mercury) (e.g. Hartmann and Neukum, 2001; Ivanov et al., 2002). Similarly, size-frequency distributions of volcanoes have been used to examine how melt penetrates the tectonic plates (e.g. Wessel, 2001; Hillier and Watts, 2007). Aeolian dunes' formation can be constrained by their sizes (e.g. Durán, 2011; Bo et al., 2011). In sub-glacial geomorphology "flow sets" of proximal bedforms thought to created by the same ice motion occur exponentially less often as their size increases (Fig. 2), which arguably indicates that substantive elements of the ice-sediment-water system beneath ice sheets contain randomness (Hillier et al., 2013).

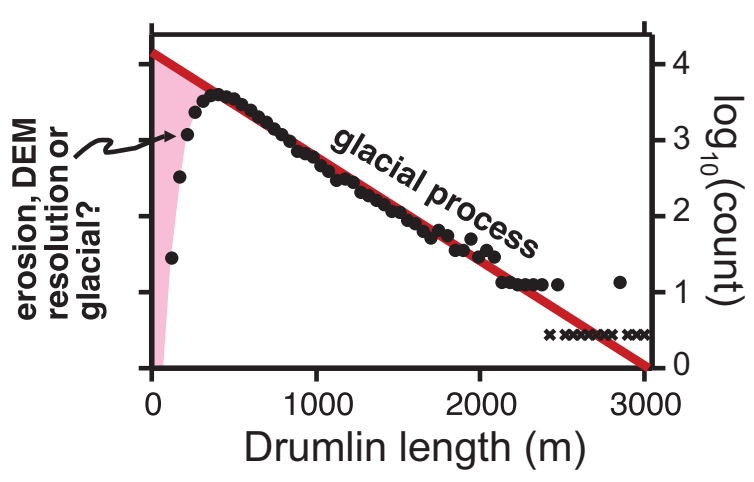

Figure 2. Semi-logarithmic frequency plot of the lengths, $L$, of UK drumlins adapted from Hillier et al. (2013). Black dots are data digitised from Fig. 8 of Clark et al. (2009), with a bin width of $\sim 50 \mathrm{~m}$. Red line is the exponential trend. Crosses indicate zero counts, placed at a nominal value of 1 . Aspects of the curve are speculatively associated with processes, i.e. glacial, or related to erosion and DEM construction.

Quantitative analysis can also provide constraints when applied to linear features and spatially continuous measures. Channel geometry is measured to investigate the influences of tectonic or climatic landscape forcing (e.g. Brummer and Montgomery, 2003; Wohl, 2004; Sofia et al., 2015), and channel networks are identified to evaluate hydrological responses in floodplains (e.g. Cazorzi et al., 2013). Continuous measures such as curvature can arguably distinguish dominant geomorphic processes (e.g. diffusive vs. fluvial) (e.g. Tarolli and Dalla Fontana, 2009; Lashermes et al., 2007), and can be designed to detect the presence of anthropogenic features (e.g. agricultural terraces) (Sofia et al., 2014). They can also be used to estimate the probability of landsliding during rainstorms or for (semi-)automated geomorphological mapping (e.g. Tarolli and Tarboton, 2006; Milledge et al., 2009; Eisank et al., 2014). Thus, such quantifications also have value for geomorphic understanding. Importantly, these 
examples illustrate how a robust, reproducible, and quantitative approach can be used to develop our understanding of process.

Any enhanced use of landform observations, however, relies on us being able to trust what we have mapped or quantified. Specifically, the key question is, in terms of precision, accuracy, and mapping completeness, to what extent is it possible to trust the metrics derived from morphometric quantification of the landforms or surface recorded in the DEMs?

One way around this difficulty is to derive descriptive statistics that are as robust as possible to observational shortcomings (e.g. Hillier et al., 2013; Sofia et al., 2013; Tseng et al., 2015). Another solution is to assess the quality of the morphological mapping and quantification, perhaps either by an estimate of data completeness or quality (e.g. Hillier and Watts, 2007) or by traditional inter-comparisons between mappers (e.g. Podwysocki et al., 1975; Siegal, 1977; Smith and Clark, 2005) or techniques (e.g. Sithole and Vosselman, 2004). The difficulty with robust statistics is that they will still be distorted if shortcomings are substantial (e.g. Hillier and Watts, 2004), and inter-comparisons can only ever yield relative levels of success and even complete agreement is inconclusive; all techniques, mappers, or techniques calibrated to mappers (e.g. Robb et al., 2015) may be systematically missing things (e.g. smaller features; Eisank et al., 2014; Hillier et al., 2014). Furthermore, it is simply not possible to calculate or estimate the magnitude of potential systematic biases within these approaches. An alternative is to verify each method or result against suitable features or properties known a priori within a suitably constructed test DEM. Thus designed landscapes, or "synthetic" DEMs, can give strong "absolute" answers (e.g. $84 \%$ of valley heads in the real landscape are identified correctly), and may be vital in allowing us to proceed better with uncertainty-aware landscape analysis to examine physical processes.

Synthetic DEMs built by directly using postulated governing equations that encapsulate processes, or landscape evolution models (LEMs) (e.g. Chase, 1992), are another key part of examining the form-process link. By altering their constants (e.g. rainfall, hillslope diffusivity) and mathematical construction they can give insights into the drivers and impacts of physical processes (e.g. Willgoose et al., 1991; Montgomery and Dietrich, 1994; Miyamoto and Sasaki, 1997). LEMs are, however, not yet the whole solution since, to be securely compared to reality, equivalent landforms within both DEM types must still be robustly quantified, sometimes making validation or calibration very difficult (e.g. Martin and Church, 2004; DeLong et al., 2011). It is also possible to use synthetic DEMs to test for inaccuracies in DEMs created by LEMs or by measuring a landscape (i.e. "make" in Fig. 1); one example of this might be requiring that LEMs replicate analytic solutions of the governing equations for simple geometries and forcings. Ultimately, all synthetic DEMs originate in a conceptual view of at least one aspect of a landscape (e.g. drumlin shape, stream-power-based fluvial behaviour).

This note introduces synthetic tests and DEMs and then outlines a typology of synthetic DEMs along with their benefits, challenges, and future potential to provide constraints and insights. Note that "virtual" and "artificial" are used interchangeably with "synthetic", as they are in the literature.

\section{Synthetic tests and the potential uses of synthetic DEMs}

In fields such as geophysics it is standard to verify any method against its performance on some idealised or "synthetic" data. A well-documented example is the classic "synthetic checkerboard" test (e.g. Dziewonski et al., 1977; Saygin and Kennett, 2010) used in tomographic imaging of the Earth's interior. Broadly, there are four requisite stages for such a test based upon synthetic data (e.g. Nolet et al., 2007).

1. Construct a synthetic input including any features of interest (e.g. the morphology of a landform).

2. Create the synthetic data that resemble the observed data, for instance adding suitable noise.

3. Invert the synthetic data using the same numerical approach applied to the observed data.

4. Compare the inverted result with the synthetic input to see how well the assumed synthetic input (e.g. landform) is recovered.

The difficulty always lies in generating a suitable, statistically representative synthetic; in the case of geomorphology the task is to create an "appropriate" synthetic landscape or DEM that is realistic enough in the aspects under investigation.

DEMs containing a synthetic component have been employed in "synthetic tests" to assess approaches used to estimate the fractal dimension of topography (Malinverno, 1989; Rodriguez-Iturbe and Rinaldo, 1997; Tate, 1998a, b), slope and aspect (Zhou and Liu, 2004), land surface parameters (LSPs) (e.g. Wechsler and Kroll, 2006; Sofia et al., 2013), and the reliability of DEMs (e.g. Fischer, 1998; Oksanen and Sarjakoski, 2010). Additionally, they have been used to evaluate how well some features (e.g. river networks, terraces) are identified (Pelletier, 2013; Sofia et al., 2014) and others (e.g. submarine volcanoes and drumlins) are isolated in 3-D (i.e. their volumes explicitly delimited) (Wessel, 1998; Hillier, 2008; Kim and Wessel, 2008; Hillier and Smith, 2014). Synthetics have also been used to assess algorithms quantifying landscape processes such as flow routing (e.g. Pelletier, 2010) and to give a first insight into how effective the manual mapping of glacial bedforms is (Hillier et al., 2014). Often, when including randomness (e.g. in locations or noise) in a Monte Carlo approach, multiple realisations 
of a landscape (e.g. $n=10$ or 1000) are used to understand uncertainty and variability and more tightly constrain results (e.g. Heuvenlink, 1998; Raaflaub and Collins, 2006; Wechsler and Kroll, 2006). The large (e.g. 60-66\% in Hillier et al., 2014) and systematic trends and biases that studies so far have uncovered indicates that the uses of synthetic tests in geomorphology should be, arguably, similar in extent and function to the current use of inferential statistics; namely they are a demonstration that the observation claimed actually exists or the method actually works. Some potential applications of synthetic tests in geomorphology can be categorised as follows:

- Assessing the impact of "noise" (e.g. Sofia et al., 2013; Zhou and Liu, 2002, 2008) that could be instrumental, anthropogenic (e.g. houses), or natural (e.g. vegetation). This applies to making DEMs from measurement, and making quantitative observations from any DEM.

- When observing, verifying that a geomorphic signature is actually characteristic of a particular landform type of interest, rather than other morphologies in a study area (e.g. Conway et al., 2011; Sofia et al., 2014).

- Quantifying extraction of features using metrics such as completeness and reliability (e.g. Hillier et al., 2014; Eisank et al., 2014); in this the key advantage is that synthetics give "absolute" measures of accuracy simply not possible with traditional mapper inter-comparisons (e.g. 34-40\% of drumlins can be detected).

- Assessing filtering or other techniques used to manipulate a DEM (e.g. Hillier and Smith, 2014), whose choice would otherwise be subjective.

- Evaluating the sensitivity of algorithms quantifying geomorphic processes to modelling assumptions, such as DEM resolution (e.g. Pelletier, 2010).

- Determining whether or not LEMs have been correctly constructed (i.e. "make" in Fig. 1).

Ultimately, the geomorphological intention is to use synthetic DEMs to examine more clearly the expression of physical processes. Rigour added to geomorphological observations through testing with synthetic DEMs will, we believe, ultimately link physics-driven models of processes to morphological observations, allowing quantitative hypotheses to be formulated and tested (e.g. see McCoy, 2015). This is illustrated in Fig. 1, the crux of which is that it is necessary to quantify landscape properties to rigorously reconcile DEMs, with some main elements of this described in more detail below.

If arguably realistic forms can be generated directly by a physics-based model (e.g. Dunlop et al., 2008; Refice et al., 2012; Brown, 2014) creating a synthetic DEM, these may in principle be linked directly to reality if suitably equivalent field sites can be found, measured, and recorded in a
DEM. The effects of various constants (e.g. rainfall), conditions, and processes in the physical models on observables can be viewed and compared to reality by the simple expedient of turning them off or amplifying them, of course allowing carefully for appropriate initial and boundary conditions. Comparisons have been qualitative (e.g. Kaufman, 2001), but they can provide more powerful insights if they apply consistent mapping or quantification procedures (e.g. Willgoose, 1994). Thus, creating a form-process link will still depend critically upon understanding any errors or biases in landform morphometrics (e.g. in size-frequency distributions, dominant wavelength) for both the measured and generated landscapes (i.e. "observe" in Fig. 1). The appropriate metrics are better understood for some landforms than for others, and it is only possible to adequately assess their efficacy (i.e. in an absolute sense) with tests involving a priori information and a DEM to apply the morphometric extraction method to, or by our definition using a synthetic DEM. If laboratory experiment replaces LEM-derived synthetic DEMs in the paragraph above, the same logic applies.

For a landform that it is not yet possible to create numerically from first mathematical principles, other routes exist. The challenge is to securely relate the driving process (e.g. tectonic uplift rate) to a measure of morphology (i.e. "conceptual model" to "landscape properties" in Fig. 1), perhaps using its variability within geographical areas. For example, drumlin sizes observed for a number of flow sets might be compared to characteristics of flow within a modelled ice sheet (e.g. flow velocity) representative of the area of the flow set. Statistical models can be formulated that link sizefrequency observations to parameters in numerical ice-flow models (Hillier et al., 2016), but even potential empirical rules about timing (e.g. immediately before deglaciation) and the relationships to ice flow (e.g. size directly proportional to velocity) could be tested. Robustly determined observational metrics would be needed for such an inversion - i.e. synthetic tests are needed. Realistic models are likely to contain stochastic elements (e.g. Tucker et al., 2001); thus a statistical understanding may help to identity more effectively appropriate parameterisations for size observations than testing a variety of established distributions (e.g. the Weibull distribution; van der Mark, 2008). Observational robustness is desirable in this case, but also for approaches that make predictions about landscape properties directly from conceptual models, for instance dominant wavelengths (e.g. Anderson, 1953; Venditti, 2012).

A final use of synthetic DEMs is examining "what if" engineering scenarios as they affect behaviours such as hydrological processes (e.g. Tarolli et al., 2015). This may be somewhat tangential, but imposing a proposed artificial geometry onto a measured DEM as a way of testing an artificial geometry to be created on the part of the Earth's surface is clearly a legitimate pursuit. 


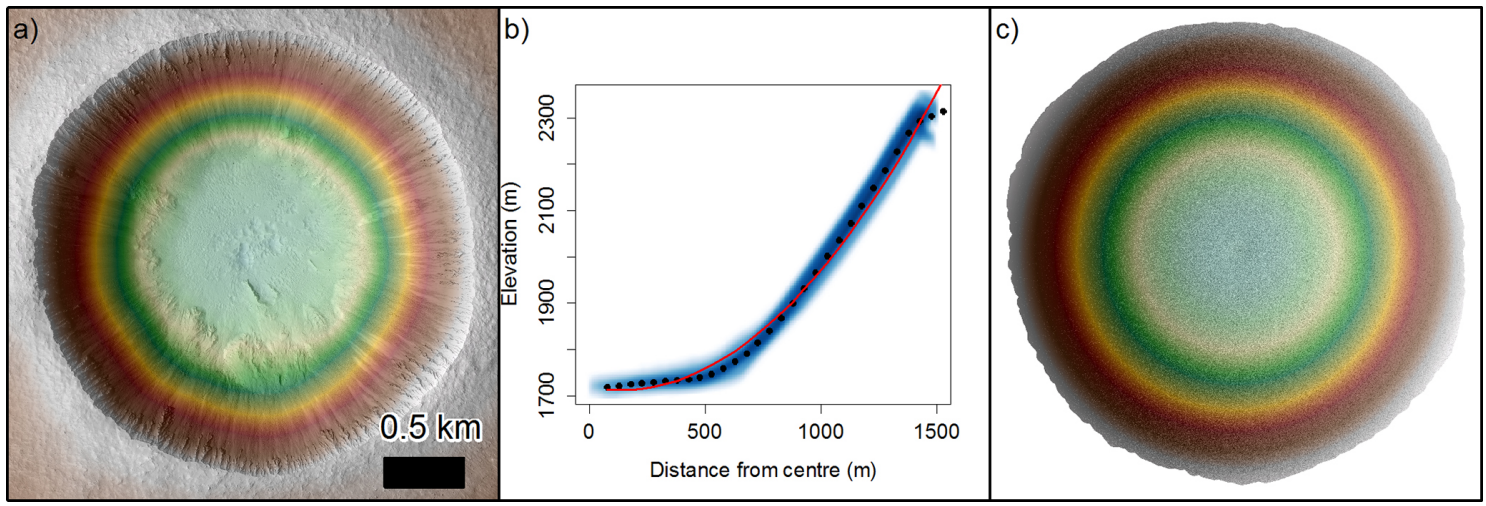

Figure 3. (a) HiRISE image of Zumba crater on Mars coloured according to elevation; HiRISE image DT2EA_002118_1510_003608_1510_A01 and DEM DTEEC_002118_1510_003608_1510_A01, credit NASA/JPL/UofA. (b) Radial elevation profile; blue shading illustrates the data distribution, black dots are averages within $50 \mathrm{~m}$ distance bins, and the red line is a parabolic fit to those points. (c) A synthetic crater created by rotating the parabolic equation, overlain by uncorrelated Gaussian noise and displayed as in (a).

\section{Synthetic DEM typology}

Synthetic DEMs are only useful if they can be constructed, and their construction must be from or clearly identify "components" (e.g. a landforms layer). In contrast to viewing a landscape as plan-view regions, height in DEMs can be described at any location $(x, y)$ as the sum of $n$ "components" (Eq. 1) (e.g. Wren, 1973; Wessel, 1998; Hillier and Smith, 2008), namely $H_{\mathrm{DEM}}=H_{1}+H_{2}+\ldots H_{n}$. Conceptually, these components lie on top of each other, like geological strata, and extend across the entire DEM although they may have zero thickness for few or many parts of it.

For landform analysis the first component would typically be "noise" (e.g. DEM error, or surface "clutter" such as trees), the small-scale height variations not genetically related to the landform. A second component would be the landforms themselves, perhaps overlying a third component of larger-scale trends (e.g. $10 \mathrm{~km}$ wide smoothly undulating hills). However, in the limit, only one component is actually required, and how the components are constructed will vary depending upon the purpose of the synthetic DEM. Furthermore, the synthetic DEM might mix idealised, created components with real ones. Typically randomness is involved in the creation of statistical synthetics, and multiple realisations of landscapes may be created. The broad approaches to constructing synthetic DEMs are outlined in the typology below.

\subsection{Simple and statistical}

Perhaps the simplest synthetic DEMs are those constructed by using basic geometries as building blocks such as cones, Gaussian functions, and planes or other surfaces defined by simple equations (e.g. Hodgson, 1995; Wessel, 1997; Jones, 1998; Kim and Wessel, 2008; Hillier, 2008; Pelletier, 2010; Qin et al., 2012); admittedly, some functions may be less simple (e.g. Pelletier, 2013; Minár et al., 2013). Typically, generalised shapes (e.g. 2-D Gaussian, rotated parabola) are formulated based upon visual or statistical fitting of the functions to measured morphologies (e.g. Conway et al., 2011; Hillier and Smith, 2012; Pelletier, 2013) (Fig. 3); fits may not be perfect (Fig. 3b), highlighting that all synthetic DEMs are simplifications of reality.

These synthetics do not contain the complexity in the observed landscape, or necessarily have realistic statistical properties, but they have the advantages of being simple to construct and understand, and noise can be entirely omitted or modified with certainty in order to investigate data errors. They contain the key morphologies under investigation and are perfectly sufficient for some tests; for example, are approximately conical submarine volcanoes of variable size effectively isolated even when upon a slope? (Fig. 4). Statistically generated "noise" can be added to simple synthetic DEMs to assess the degradation caused (e.g. Zhou and Liu, 2004; Jordan and Watts, 2005), but for results to be meaningful, its statistical distribution (e.g. Gaussian, uniform), length scale of correlation, and any non-stationarity must be correct (e.g. Fischer, 1998, Sofia et al., 2013).

Whole landscapes can be generated statistically using fractals (e.g. Mandelbrot, 1983) or multi-fractals (Fig. 5a) (e.g. Gilbert, 1989; Schertzer and Lovejoy, 1989; Weissel et al., 1994; Cheng and Agterbeg, 1996), and these can be useful if the construction matches closely the element of reality being considered (e.g. uncorrelated, fractal in Swain and Kirby, 2003). Even multi-fractal landscapes, however, may not be an adequate representation without considering properties such as anisotropy (e.g. Evans and McClean, 1995; Gagon et al., 2006) and characteristic scales (e.g. Perron et al., 2008) if they are important in a particular circumstance. A limitation of these purely statistically generated, or statistically altered, DEMs for landform analysis is that they do 
a)

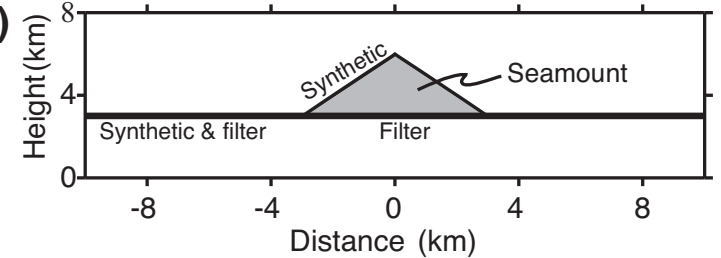

b)

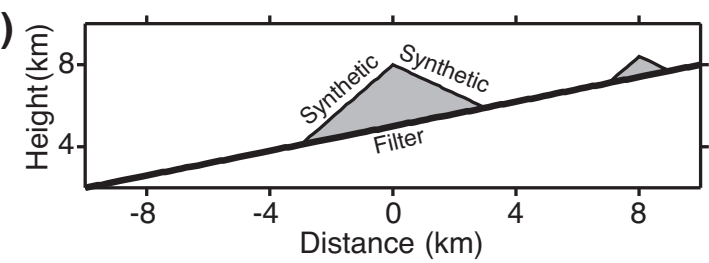

Figure 4. (a) A simple 2-D (i.e. distance-height profile) synthetic seamount (grey shading) (Hillier, 2008), which following Kim and Wessel (2008) is conical with a radius of $3 \mathrm{~km}$ and summit height of $3 \mathrm{~km}$ above the surrounding seafloor. The thin black line is the synthetic topography, and the thick black line the filter's output. (b) A more demanding test of two variably sized seamounts upon a sloping surface.

not explicitly contain spatially distinct, isolated features (i.e. landforms are not labelled as such during generation).

\subsection{Landscape evolution models}

DEMs resembling real landscapes can also be created by the application of mathematical characterisations of physical processes in numerical models typically known as "landscape evolution models" (LEMs) (Fig. 5b) (e.g. Chase, 1992; Braun and Sambridge, 1997); implementation approaches can vary (see Griffin, 1987). These now incorporate numerous processes (e.g. Tucker and Hancock, 2010; Refice et al., 2012); for example, bedrock landslides (e.g. Densmore et al., 1998), flexure of the lithosphere (e.g. Lane et al., 2008), and erosion by ice flow within valleys (e.g. Harbor, 1992; Brocklehurst and Wipple, 2004; Amundson and Iverson, 2006; Tomkin, 2009), including when this is thermo-mechanically coupled to ice sheets (e.g. Jamieson et al., 2008). Models of the evolution of single classes of a feature (e.g. bedforms) and simpler 2-D configurations (i.e. $x-z$ profiles) fall within this class of model (cf. Dunlop et al., 2008; Zhang et al., 2010; Brown et al., 2014). Simple geometries or measured landscapes may be used as an input (e.g. DeLong et al., 2011; Refice et al., 2012; Baartman et al., 2013; Hancock et al., 2015).
Several difficulties prevent these models from, as yet, being ideal solutions. In terms of testing observational methods, the first difficulty is that the method of generating some landforms, such as drumlins, from first principles is often contested (cf. Hindmarsh, 1998; Schoof, 2007; Pelletier, 2008), and it is not computationally practical to include certain processes, such as impact crater formation in the MARSSIM model (Howard, 2007). The simulation of rivers illustrates an area where there is progress, but also much to do (cf. Coulthard et al., 2013; Brown et al., 2014). In general, a highly accurate and widely accepted unified model is still some way off. The second difficulty is that these models do not currently associate processes with a type of landform. For instance, a bedrock failure process is a bedrock failure process, not a bedrock failure process explicitly making a V-shaped valley. Equally, sediment is not tagged as making a floodplain. Thus, the number and location of defined features are not known a priori. This can be seen as a strength of the models, but means that creating a secure link from process to landforms as observed in reality requires a step in which consistent mapping or quantification procedures are applied to both measured and simulated DEMs. This is not easy (e.g. DeLong, 2011). The lack of a priori features may also be the reason that, although LEMs have great potential to create DEMs for synthetic tests of landform mapping or extraction methodologies, we are not aware of this being done. Like simple or statistical synthetic DEMs, synthetics created by a LEM have the advantage of being free from errors associated with DEM measurement (e.g. instrumental, processing).

\subsection{Laboratory-derived}

If LEM-derived DEMs can be considered as synthetic DEMs, then laboratory-derived ones (e.g. Hancock and Willgoose, 2001; Lague et al., 2003; Graveleau and Dominguez, 2008; Sweeny et al., 2015) could also be considered so. Such experiments can control variables such as rainfall and uplift that are impossible to precisely control in nature (e.g. Sweeny et al., 2015), but limitations in realism exist particularly in scaling (see Paola et al., 2009).

\subsection{Complex geometrical}

A possible class of synthetic DEM is one that uses simple or statistical building blocks, but constructed in a more complex fashion. For instance, multiple idealised shapes can be given additional observed attributes (e.g. spatial clustering, sizefrequency realism) (e.g. Howard, 2007; Hillier and Smith, 2012), but such DEMs have so far contained other elements of realism as well, perhaps making them better described as hybrids. 

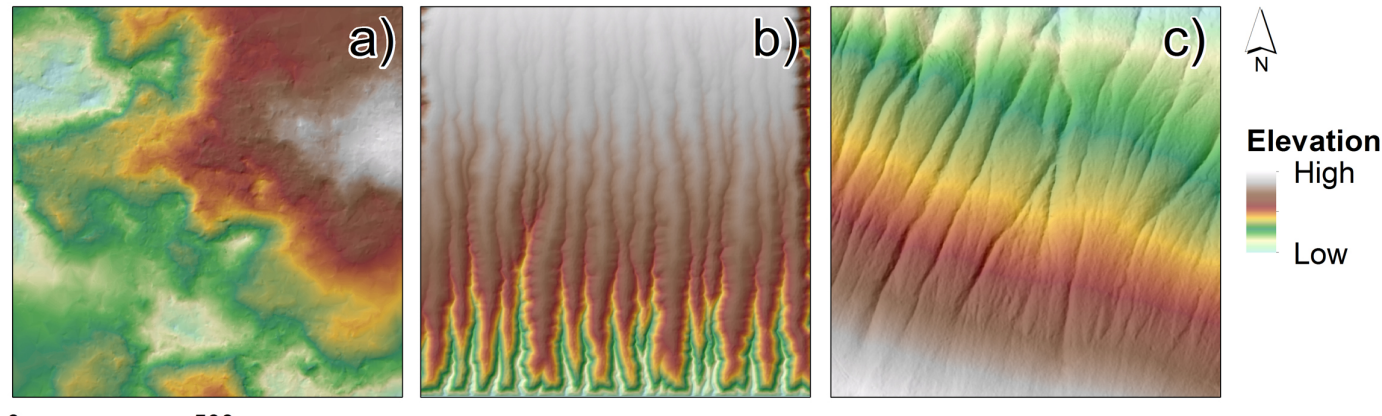

0

$500 \mathrm{~m}$

Figure 5. Comparison of simulated DEMs in (a) and (b) with lidar measurement of a real landscape in the south of Italy in (c). (a) Fractional Brownian motion (Mandelbrot, 1983); initial roughness of the surface $=0.2$, initial elevation of the surface $=0.0$, and change of roughness over change of terrain $=0.005$. Output is dimensionless, but is effectively given the same scale and resolution as (c) by assigning each pixel a $2 \times 2 \mathrm{~m}$ size. (b) A landscape model (Refice et al., 2012) that evolves through time a southward-dipping initial topography containing small-scale randomness, with all four boundaries closed except the lower right corner. Simulated time is $\sim 30 \mathrm{kyr}$ and the run parameters are tectonic uplift $u_{f}=1 \mathrm{~mm} \mathrm{yr}^{-1}$; diffusivity constant $k_{\mathrm{d}}=0.2 \mathrm{~m}^{2} \mathrm{yr}^{-1}$; with channelling parameters of $K_{\mathrm{c}}=10^{-4} \mathrm{~m}^{(1-2 m)} \mathrm{yr}^{-1}, m=0.5$, and $n=1$. The spatial dimensions of (b) are as in (c). Centroid in (c) is $14^{\circ} 37^{\prime} 59.46^{\prime \prime} \mathrm{E}, 40^{\circ} 43^{\prime} 25.80^{\prime \prime} \mathrm{N}$.

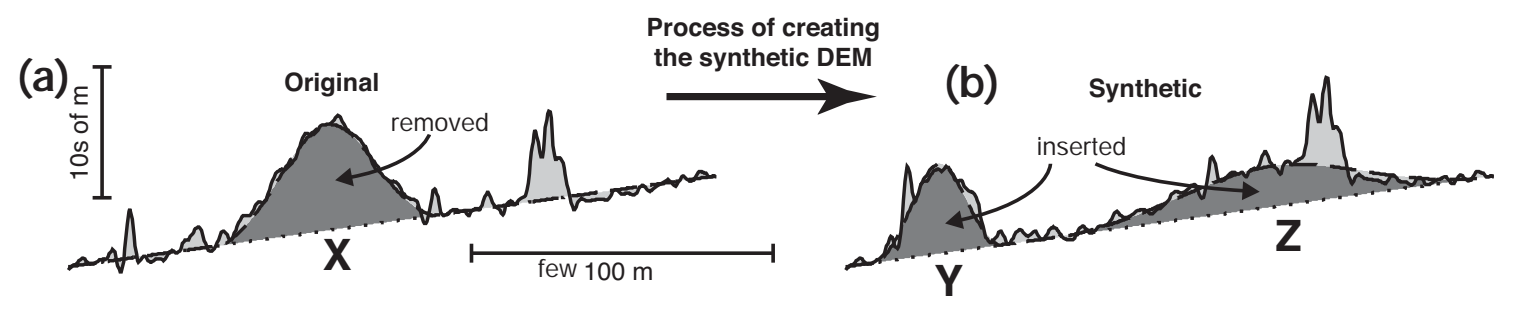

Figure 6. Idealised distance-height profiles to illustrate the process used by Hillier and Smith (2012) to create synthetic DEMs. There are three "components". Drumlins, which are shaded dark grey, rise above a regional trend indicated by a dotted line. These are overprinted by "clutter" or "noise" shown in light grey. (a) In the process the upper and lower surfaces of the drumlin $(X)$ are estimated to define it, and its height is subtracted from the measured DEM. (b) Two Gaussian-shaped drumlins $(Y$ and $Z$ ) are then inserted by adding their height to create the synthetic DEM.

\subsection{Hybrid}

A "hybrid" class of synthetic DEM contains, for reasons of practicality, elements of the other classes. Typically, either a morphology whose key properties cannot currently be readily simulated is retained (e.g. most or all of a measured DEM) or an idealised but observationally constrained component is added (e.g. terraces; Sofia et al., 2014), or both. The spectrum of what is possible is illustrated by the, relatively rare, studies using hybrid synthetic DEMs in geomorphology.

A first example of a hybrid synthetic DEM is impact crater formation in the MARSSIM model (Howard, 2007). This evolution model does not dynamically model crater formation. Instead, randomly located craters are assigned shapes from a catalogue of measurements of individual fresh craters on Mars and given sizes from a power-law distribution. This introduces certain assumptions, such as the fresh craters being representative, but avoids complexity. A second example deals with the quantification of glacial bedforms, illustrated with drumlins (Hillier and Smith, 2012, 2014; Hillier et al., 2014). It is the association of the bedforms with underly- ing trends (i.e. "hills") and complex and spatially structured "noise" (e.g. trees, roads, houses) that makes the quantification difficult; in particular, this noise is problematic, and geomorphological analyses have yet to attempt simulating it. The approach taken was therefore to circumvent this issue entirely by leaving the hills and noise as they were, and moving the drumlins such that they were randomly positioned with respect to these problems for identification (Fig. 6). Orientations and spatial density distribution (i.e. number per $\mathrm{km}^{2}$ ) were preserved, as were the geometries (i.e. heightwidth-length triplets) of the 173 drumlins shuffled around. In these synthetics (Fig. 7), the number and location of defined features are known a priori such that sizes and locations of mapped discrete landforms can be compared to synthetic ones directly. Similarly, but by assuming the highestquality measured lidar DEMs were perfect, even if this is debatable, it is possible to circumvent the need to generate statistically realistic landscapes when investigating DEM errors (Raaflaub and Collins, 2006; Sofia et al., 2013). Anthropogenic elements (e.g. open-cast mines, terraces) visually de- 

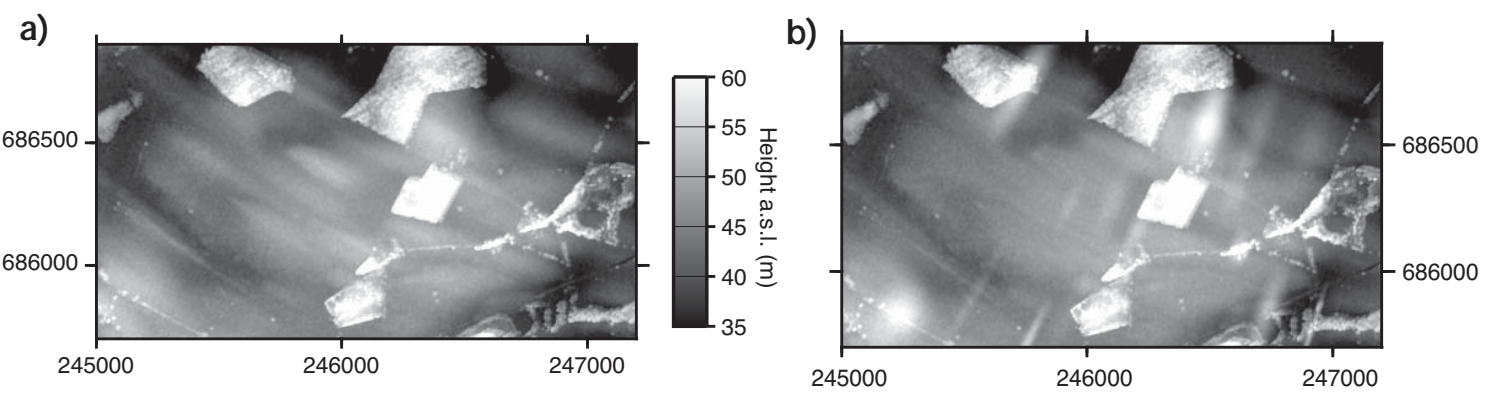

Figure 7. Illustration of a real DEM in (a) and a "hybrid" synthetic generated from (b). Method used is as in Fig. 6 (Hillier and Smith, 2012 ), adapted to locally align drumlins with each other (Hillier et al., 2014). Map coordinates are of the British National Grid (5 m grid). Synthetic drumlins were orientated at $90^{\circ}$ to the original ones to avoid any possible confusion with any incompletely removed original ice-flow fabric during the mapping exercise.

termined to be reasonable can also be added (e.g. Baartman et al., 2015), for instance, to a 2-D multi-fractal statistical landscape (Sofia et al., 2104; Chen et al., 2015).

\section{Discussion}

By providing an a priori known answer to test against, synthetic DEMs or DEMs containing a synthetic component have some clear and powerful advantages in geomorphological analyses. They can be used to test errors and systematic or random biases and to unpick potential sources of misinterpretation. Furthermore, they give absolute answers (e.g. $47 \%$ of all actual drumlins $H>3 \mathrm{~m}$ are mapped) to questions about accuracy that are simply not obtainable by other means, and are often considered "objective". Through this they provide a route to answering key questions about geomorphic processes (e.g. Fig. 1). There are, however, complexities surrounding these statements, which are less commonly recognised. There are issues of objectivity, realism, circularity, and the cost in time and effort of constructing synthetics.

Whilst the conclusions reached through the use of synthetics may be simplistically thought of as objective, it is more accurate to say that they are quantitative and reproducible, and that they are likely to be significantly less subjective. Without perfect, all-purpose synthetics an element of subjectivity will remain in the choices made when designing the test DEM. Hillier and Smith (2012) illustrate some choices and a logical justification for them. Manually selecting data to test against (e.g. Sithole and Vosselman, 2004; Hillier and Watts, 2004 ) is faster in some circumstances, if more subjective. Reproducibility makes testing using synthetic DEMs superior to subjective visual verification, even if synthetic tests later indicate the visual estimate was a reasonable solution (Hillier and Smith, 2012, 2014). Pre-existing synthetic DEMs, however, are entirely objective means for inter-comparison for future studies (e.g. Eisank et al., 2014).

A thorny question regarding synthetics is, how realistic is realistic enough? At one limit, it is notable that even extreme simplifications such as conical volcanoes can give significant and useful first-order insights (e.g. Kim and Wessel, 2008; Tarolli et al., 2015). At the other limit, synthetic DEMs are not used on the basis that their applicability to real data sets is questioned (e.g. Robb et al., 2015). Lacking a perfect set of properties, however, should not be taken to invalidate tests using a synthetic DEM; in statistics, for instance, Student's $t$ test, underpinned by its idealised Gaussian distribution, is widely used, although observations are rarely perfectly normal. A challenge then is to determine a generalised objective framework or workflow to assess the sufficiency of the realism of synthetic DEMs, but in its absence, what can be done? Deficiencies can be visually identified. For instance, if spatial resolution is raised as an issue, it can either be matched to the observed data or varied for a sensitivity test. If a particular statistical property and its variation with scale is key, it can be measured to ensure it is realistic in the synthetic. Therefore, if a clearly stated set of properties argued to be most relevant to any given research task are faithfully reproduced in synthetics, we believe they will provide useful insights. Ultimately, however, practitioners within a peer group must decide what is convincing, performing additional tests if necessary. For example, Hillier and Smith (2012) did not locally align neighbouring drumlins with each other, but participants of the GMapping workshop (Hillier et al., 2014) felt that this was critical. Modified DEMs with this property included were therefore provided, although in the end this proved to be a minor effect. Similarly, what must be captured well in a synthetic DEM may critically vary between studies. This is exemplified by the impact of life (e.g. buildings, earthworks, trees, eco-geomorphic work by worms), which may either be inconvenient "noise" (e.g. Hillier and Smith, 2012) or the morphology of interest (e.g. Dietrich and Perron, 2006).

A more subtle potential issue is circularity. It is important to avoid basing aspects of a synthetic DEM on an assumption and then using it to support the assumption. This is easily avoided in simple synthetic DEMs, but a synthetic DEM based on a landscape evolution model, for instance, should not later be justified because a search algorithm trained on it finds only similar features in a real landscape; the algorithm 
might just be missing things in the real landscape that differ from what it has been trained to detect. A similar issue was faced by Hillier and Smith (2012), but this was demonstrably avoided as the filter later found to be optimal was not the one initially assumed (Hillier and Smith, 2014).

Thus, subjectivity is reduced, even synthetic tests using basic DEMs can give some insight, and circularity can be avoided. On balance we argue that, if designed appropriately and used with appropriate care, tests using synthetic DEMs are worth the cost in time as they can be used to access results and insights of real significance and power. Exactly the same can be said for the application of statistical techniques, and so it seems reasonable to advocate the use of synthetic tests with similar strength.

By making observations more robust, synthetic tests using synthetic DEMs containing a priori known landforms have the potential to strengthen the insights that can be gained through synthetic DEMs generated using physics-based numerical models, i.e. LEMs. LEMs can provide useful insights, but they are not the entire solution; firstly, they cannot model all processes yet, and secondly they are insufficient without synthetic tests to secure the observational part of the linkage between measured and generated DEMs. It is also worth noting that LEMs are not the only route to creating a from-process link since the other routes described (e.g. statistical) also provide a quantitative means of establishing a form-process link even without a LEM. Thus, there are a number of valid types and specific uses of synthetic DEMs, but in combination we believe that they form a vital underpinning for the quantitative future of landform analysis (e.g. see McCoy, 2015).

\section{Conclusions}

From this discussion on the uses of synthetic digital landscapes (i.e. DEMs), or synthetic elements within them, the following overarching points can be drawn.

Synthetic DEMs can help to link physics-based models of processes to morphological observations, allowing quantitative hypotheses to be formulated and tested; importantly, this is not only through the use of landscape evolution models.

- By establishing "absolute" answers, tests using synthetic DEMs containing a priori known landforms are a powerful tool with which to test and add rigour to geomorphological observations, and arguably should become as standard as statistical tests in geomorphology or synthetic test data in other arenas (e.g. geophysics).

- A "perfect" synthetic DEM faithfully representing all aspects of an environment is likely impractical or impossible to create at present, but is not necessary.

- Synthetic DEMs for tests may be easy and simple to construct, yet still provide valuable insights.
- Synthetic tests using DEMs should be tailored to each research question, and their appropriateness to the key aspects of each inquiry (e.g. resolution, biases, and sensitivities) should be set out clearly and logically.

Acknowledgements. Lidar data in Fig. 5c were provided by the Italian Ministry for Environment, Land and Sea (Ministero dell'Ambiente e della Tutela del Territorio e del Mare, MATTM), as part of the PST-A framework. The GMT software was used (Wessel and Smith, 1998). S. J. Conway was funded by the Leverhulme Trust (grant RPG-397). We thank J. Pelletier, I. Evans, and an anonymous reviewer for their fair and insightful comments.

Edited by: D. Parsons

\section{References}

Amundson, J. M. and Iverson, N. R.: Testing a glacial erosion rule using hang heights of hanging valleys, Jasper National Park, Alberta, Canada. J. Geophys. Res.-Earth, 111, F01020, doi:10.1029/2005JF000359, 2006.

Anderson, A. G.: The characteristics of sediment waves formed on open channels, Proceedings of the Third Mid-Western Conference on Fluid Mechanics, 23-25 March 1953, University of Missouri, Missoula, USA, 397-395, 1953.

Baartman, J. E. M., Masselink, R., Keesstra, S. D., and Temme, A. J. A. M.: Linking landscape morphological complexity and sediment connectivity, Earth Surf. Proc. Land., 38, 1457-1471, doi:10.1002/esp.3434, 2013.

Balci, O.: Verification, Validation, and Testing, in: Handbook of Simulation: Principles, Advances, Applications, and Practice, edited by: Banks, J., Wiley, New York, USA, 335-393, 1998.

Beven, K. J. and Kirkby, M. J.: A physically based variable contributing area model of basin hydrology, Hydrol. Sci. Bull., 24, 43-69, 1979.

Bo, T. and X. Zheng: The formation and evolution of aeolian dune fields under unidirectional wind, Geomorphology, 134, 408-416, doi:10.1016/j.geomorph.2011.07.014, 2011.

Braun, J. and Sambridge, M.: Modelling landscape evolution on geological time scales: A new method based on irregular spatial discretization, Basin Res., 9, 27-52, 1997.

Brocklehurst, S. H. and Wipple, K. X.: Hypsometry of glaciated landscapes, Earth Surf. Proc. Land., 29, 907-926, 2004.

Brown, R. A., Pasternack, G. B., and Wallender, W. W.: Synthetic river valleys: Creating prescribed topography for form-process inquiry and river rehabilitation design, Geomorphology, 214, 4055, 2014.

Brummer, C. J. and Montgomery, D. R.: Downstream coarsening in headwater channels, Water Resour. Res., 39, 1294, doi:10.1029/2003WR001981, 2003.

Cazorzi, F., Dalla Fontana, G., De Luca, A., Sofia, G., and Tarolli, P.: Drainage network detection and assessment of network storage capacity in agrarian landscape, Hydrol. Process., 27, 541553. doi:10.1002/hyp.9224, 2013.

Chase, C. G.: Fluvial landscupting and the fractal dimension of topography, Geomorphology, 5, 39-57, 1992. 
Chen, J., Li, L., Chang, K., Sofia, G., and Tarolli, P.: Open-pit mining geomorphic feature characterization, Int. J. Appl. Earth. Obs., 42, 76-86, ISSN 0303-2434, doi:10.1016/j.jag.2015.05.001, 2015.

Cheng, Q. M. and Agterberg, F. P.: Multi-fractal modelling and spatial statistics, Math. Geol., 28, 1-16, 1996.

Clark, C. D., Hughes, A. L. C., Greenwood, S. L., Spagnolo, M., and $\mathrm{Ng}$, F. S. L.: Size and shape characteristics of drumlins, derived from a large sample, and associated scaling laws, Quaternary Sci. Rev., 28, 677-692, doi:10.1016/j.quascirev.2008.08.035, 2009.

Conway, S. J., Balme, M. R., Murray, J., Towner, M. C., Okubo, C. H., and Grindrod, P. M.: The indication of Martian gully formation processes by slope-area analysis, Geol. Soc. Spec. Publ., 356, 171-201, doi:10.1144/SP356.10, 2011.

Coulthard, T. J., Neal, J. C., Bates, P. D., Ramirez, J., de Almeida, G. A. M., and Hancock, G. R.: Integrating the LISFLOOFFP 2-D hydrodynamic model with the CAESAR model: implications for modelling landscape evolution, Earth Surf. Proc. Land., 38, 1897-1906, doi:10.1002/esp.3478, 2013. DeLong, B., Pelletier, J. D., and Arnold, L.: Bedrock landscape development modeling: Calibration using field study, geochronology, and digital elevation model analysis, GSA Bull., 119, 157-173, doi:10.1130/B25866.1, 2011.

Densmore, A. L., Ellis, M. A., and Anderson, R. S.: Landsliding and the evolution of normal-fault-bounded mountains, J. Geophys. Res., 103, 15203-15219, doi:10.1029/98JB00510, 1998.

Dietrich, W. E. and Perron, J. T.: The search for a topographic signature of life, Nature, 439, 411-418, 2006.

Dunlop, P., Clark, C. D., and Hindmarsh, R. C. A.: Bed Ribbing Instability Explanation: Testing a numerical model of ribbed moraine formation arising from coupled flow of ice and subglacial sediment, J. Geophys. Res., 113, F03005, doi:10.1029/2007JF000954, 2008.

Durán, O., Schwämmle, V., Lind, P. G., and Herrmann, H. J.: Size distribution and structure of Barchan dune fields, Nonlin. Processes Geophys., 18, 455-467, doi:10.5194/npg-18-455-2011, 2011.

Dziewonski, A., Hager, B., and O'Connell, R. Large-scale heterogeneities in the lower mantle, J. Geophys. Res., 82, 239-255, 1977.

Eisank, C., Smith, M., and Hillier, J. K.: Assessment of multi-resolution segmentation for delimiting drumlins in digital elevation models, Geomorphology, 214, 452-464, doi:10.1016/j.geomorph.2014.02.028, 2014.

Evans, I. S.: Geomorphometry and landform mapping: What is a landform?, Geomorphology, 137, 94-106, doi:10.1016/j.geomorph.2010.09.029, 2012.

Evans, I. S. and McClean, C. J.: The land surface is not unifractal; variograms, cirque scale and allometry, Z. Geomorphol. Supp., 101, 127-147, 1995.

Fisher, P.: Improved modeling of elevation error with geostatistics, Geoinformatica, 2, 215-233, 1998.

Gagnon, J.-S., Lovejoy, S., and Schertzer, D.: Multifractal earth topography, Nonlin. Processes Geophys., 13, 541-570, doi:10.5194/npg-13-541-2006, 2006.

Gilbert L. E.: Are topographic data sets fractal?, Pure Appl. Geophys., 131, 241-254, 1989.
Graveleau, F. and Dominguez, S.: Analogue modelling of the interaction between tectonics, erosion and sedimentation in foreland thrust belts, C. R. Geosci., 340, 324-333, 2008.

Griffin, M. W.: A rapid method for simulating three-dimensional fluvial terrain, Earth Surf. Proc. Land., 12, 31-38, 1987.

Grohmann, C., Smith, M. J., and Riccomini, C.: Multiscale analysis of surface roughness in the Midland Valley, Scotland, IEEE T. Geosci. Remote, 49, 1200-1213, 2011.

Hancock, G. and Willgoose, G.: Use of a landscape simulator in the validation of the SIBERIA catchment evolution model: Declining equilibrium landforms, Water Resour. Res., 37, 1981-1992, 2001.

Hancock, G., Lowry, J. B. C., and Coulthard, T. J.: Catchment reconstruction - erosional stability at millennial time scales using landscape evolution models, Geomorphology, 231, 15-27, 2015.

Harbor, J. M.: Numerical Modeling of the development of U-shaped valleys by glacial erosion, Geol. Soc. Am. Bull., 104, 1364$1375,1992$.

Hartmann, W. K. and Neykum, G.: Cratering chronology and the evolution of Mars, Space Sci. Rev., 96, 165-194, 2001.

Heuvelink, G. B. M.: Error propagation in environmental modelling with GIS, Taylor \& Francis, London, UK, 1998.

Hodgson, M. E.: What cell size does the computerd slope/aspect angle represent?, Photogramm. Eng. Remote S., 61, 513-517, 1995.

Howard, A. D.: Simulating the development of martian highland landscapes through the interaction of impact cratering, fluvial erosion, and variable hydrologic forcing, Geomorphology, 91, 332-363, 2007.

Hillier, J. K.: Seamount detection and isolation with a modified wavelet transform, Basin Res., 20, 555-573, 2008.

Hillier, J. K. and Smith, M.: Residual relief separation: digital elevation model enhancement for geomorphological mapping, Earth Surf. Proc. Land., 33, 2266-2276, doi:10.1002/esp.1659, 2008.

Hillier, J. K. and Smith M.: Testing 3-D landform quantification methods with synthetic drumlins in a real DEM, Geomorphology, 153, 61-73, doi:10.1016/j.geomorph.2012.02.009, 2012. Hillier, J. K. and Smith, M. J.: Testing techniques to quantify drumlin height and volume; synthetic DEMs as a diagnostic tool, Earth Surf. Proc. Land, 39, 676-688, doi:10.1002/esp.3530, 2014.

Hillier, J. K. and Watts, A. B.: Plate-like subsidence of the East Pacific Rise - South Pacific Superswell system, J. Geophys. Res., 109, B10102, doi:10.1029/2004JB003041, 2004.

Hillier, J. K. and Watts, A. B.: Global distribution of seamounts from ship-track bathymetry data, Geophys. Res. Lett., 34, L113304, doi:10.1029/2007GL029874, 2007.

Hillier, J. K., Smith, M. J., Clark, C. D., Stokes, C. R., and Spagnolo M.: Subglacial bedforms reveal an exponential size-frequency distribution, Geomorphology, 190, 82-91, doi:10.1016/j.geomorph.2013.02.017, 2013.

Hillier, J. K.,Smithb, M. J., Armugama, R., Barrc, I., Bostond, C. M., Clarke, C. D., Elye, J., Franklf, A., Greenwoodg, S. L., Gosselinh, L., Hättestrandi, C., Hoganj, K., Hughesk, A. L. C., Livingstonee, S. J., Lovelll, H., McHenrym, M., Munozn, Y., Pellicero, X .M., Pelliterop, R., Robbq, C., Robersonr, S., Ruthers, D., Spagnolop, M., Standella, M., Stokest, C. R., Storrart, R., Tateu, N. J., and Wooldridgev, K.: Manual mapping of drumlins 
in synthetic landscapes to assess operator effectiveness, J. Maps, 11, 719-729, doi:10.1080/17445647.2014.957251, 2014.

Hillier, J. K., Kougioumtzoglou, I. A., Stokes, C. R., Smith, M. J., and Clark, C. D.: Stochastic ice-sediment dynamics could explain subglacial bedforms sizes, PlosONE, in review, 2016.

Hindmarsh, R. C. A.: Drumlinization and drumlin-forming instabilities: viscous till mechanisms, J. Glaciol., 44, 293-314, 1998.

Ivanov, B. A., Neukum, G., Bottke, W. F., and Hartmann, W. K.: The Comparison of Size-Frequency Distributions of Impact Craters and Asteroids and the Planetary Cratering Rate, Asteroids III, 89-101, 2002.

Jamieson, S., Hulton, N., and Hagdorn, M.: Modelling landscape evolution under ice sheets, Geomorphology, 97, 91-108, 2008.

Jones, K. H.: A comparison of algorithms used to compute hill slope as a property of the DEM, Comput. Geosci., 24, 315-323. doi:10.1016/S0098-3004(98)00032-6, 1998.

Jordan, T. A. and Watts, A. B.: Gravity anomalies, flexure and the elastic thickness structure of the India-Eurasia collisional system, Earth Planet. Sc. Lett., 236, 732-750, 2005.

Kaufmann, G. and Braun, J.: Modelling karst denudation on a synthetic landscape, Terra Nova, 13, 313-320, 2001.

Kim, S. and Wessel. P.: Directional median filtering for the regionalresidual separation of bathymetry, Geochem. Geophy. Geosy., 9, Q03005 doi:10.1029/2007GC001850, 2008.

Lague, D., Crave, A., and Davy, P.: Laboratory experiments simulating the geomorphic response to tectonic uplift, J. Geophys. Res., 108, 2008, doi:10.1029/2002JB001785, 2003.

Lane, N. F., Watts, A. B., and Farrant, A. R: An analysis of Cotswold topography: insights into the landscape response to denudational isostasy, J. Geol. Soc., 165, 85-103, 2008.

Lashermes, B., Foufoula-Georgiou, E., and Dietrich, W. E.: Channel network extraction from high resolution topography using wavelets, J. Geophys. Res., 34, L23S04, 2007.

Malinverno, A.: Testing linear models of seafloor topography, Pure Appl. Geohpys., 131, 139-155, 1989.

Mandelbrot, B.: The Fractal Geometry Of Nature, W. H. Freeman and Company, New York, USA, 1983.

Martin, Y. and Church, M.: Numerical modelling of landscape evolution: geomorphological perspectives, Prog. Phys. Geog., 28, 317-339, 2004.

McCoy, S.: Landscapes in the lab, Science, 349, 32-33, 2015.

Milledge, D. G., Lane, S., and Warburton, J.: The potential of digital filtering of generic topographic data for geomorphological research, Earth Surf. Proc. Land., 34, 63-74, doi:10.1002/esp.1691, 2009.

Minár, J., Jenco, M., Evans, I., Minár Jr., J., Kadlec, M., Krcho, J., Pacina, J., Burian, L., and Benová: Third-order geomorphometric variables (derivatives): definition, computation and utilization of changes of curvatures, Int. J. Geogr. Inf. Sci., 27, 1381-1402, 2013.

Miyamoto, H. and Sasaki, S.: Simulating lava flows by an improved cellular automata method, Computers and Geosciences, 23, 283 292, 1997

Montgomery, D. R. and Dietrich, W. E.: A physically-based model for topographic control on shallow landsliding, Water Resour. Res., 30, 1153-1171, 1994.

Nolet, G., Allen, R., and Zhao, D.: Mantle plume tomography, Chem. Geol., 241, 248-263, 2007.
Oksanen J. and Sarjakoski T.: Non-stationary modelling and simulation of LIDAR DEM uncertainty, Proceedings of the 9th International Symposium on Spatial Accuracy Assessment in Natural Resources and Environmental Sciences, 20-22 July 2010, Leicester, UK, 201-204, 2010.

Paola, C., Straub, K., and Mohrig, D.: The "unreasonable effectiveness" of stratigraphic and geomorphic experiments, Earth-Sci. Rev., 97, 1-43, 2009.

Pelletier, J. D.: Quantitative Modelling of Earth Surface Processes, CUP, Cambridge, UK, 185-189, ISBN 9780521855976, 2008.

Pelletier J. D.: Minimizing the grid-resolution dependence of flowrouting algorithms for geomorphic applications, Geomorphology, 122, 91-98, doi:10.1016/j.geomorph.2010.06.001, 2010.

Pelletier, J. D.: A robust, two-parameter method for the extraction of drainage networks from high-resolution digital elevation models (DEMs): Evaluation using synthetic and real-world DEMs, Water Resour. Res., 49, 75-89, doi:10.1029/2012WR012452, 2013.

Perron, J. T., Kirchner, J. W., and Dietrich, W. E.: Spectral signatures of characteristic spatial scales and nonfractal structure of landscapes, J. Geophys. Res., 113, F04003, 2008.

Petty, M. D.: Verification and Validation, in: Principles of Modeling and Simulation: A Multidisciplinary Approach, edited by: Sokolowski, J. A. and Banks, C. M., Wiley, New York, USA, 121-149, 2009.

Petty, M. D.: Verification, Validation, and Accreditation, in: Modeling and Simulation Fundamentals: Theoretical Underpinnings and Practical Domains, edited by: Sokolowski, J. A. and Banks, C. M., Wiley, New York, USA, 325-372, 2010.

Podwysocki, M. H., Moik, J. G., and Shoup, W. C.: Quantification of geologic lineaments by manual and machine processing techniques, Proceedings of the NASA Earth Resources Survey Symposium, 9-12 June 1975, NASA, Greenbelt, Maryland, USA, pp. 885-905, 1975.

Qin, J., Zhong, D., Wang, G., and Ng, S. L.: On characterization of the imbrication of armored gravel surfaces, Geomorphology, 159, 116-124, 2012.

Raaflaub, L. D. and Collins, M. J.: The effect of error in gridded digital elevation models on the estimation of topographic parameters, Environ. Modell. Softw., 21, 710-732, doi:10.1016/j.envsoft.2005.02.003, 2006.

Refice, A, Giachetta, E., and Capolongo, D.: SIGNUM: A Matlab, TIN-based landscape evolution model, Comput. Geosci., 45, 293-303, ISSN 0098-3004, doi:10.1016/j.cageo.2011.11.013, 2012.

Robb, C., Willis, I. C., Arnold, N., and Gudmundsson, S.: A semiautomated method for mapping glacial geomorphology tested at Breiðamerkurjökull, Iceland, Remote Sens. Environ., 163, 8090, 2015.

Rodriguez-Iturbe, I. and Rinaldo, A.: Fractal river basins: chance and self-organization, Cambridge University Press, Cambridge, UK, ISBN 0521-47398-5, 1997.

Saygin, E. and Kennett, B. L. N.: Ambient seismic noise tomography of Australian continent, Tectonophysics, 481, 116-125, 2010.

Schertzer, D. and Lovejoy, S.: Nonlinear Variability in Geophysics: Multifractal Simulations and Analysis, in: Fractals' Physical Origin and Properties SE - 3, Ettore Majorana International Science Series, edited by: Pietronero, L., Springer US, New York, USA, 49-79. doi:10.1007/978-1-4899-3499-4_3, 1989. 
Schoof, C.: Cavitation in deformable glacier beds, J. Appl. Math., 67, 163-1653, 2007.

Siegal, B. S.: Significance of operator variation and the angle of illumination in lineament analysis of synoptic images, Modern Geology, 6, 75-85, 1977.

Sithole, G. and Vosselman, G.: Experimental comparison of filter algorithms for bare-Earth extraction from airborne laser scanning point clouds, ISPRS J. Photogramm., 59, 85-101, 2004.

Smith, M. J. and Clark, C. D.: Methods for the visualisation of digital elevation models for landform mapping, Earth Surf. Proc. Land., 30, 885-900, 2005.

Sofia, G., Pirotti, F., and Tarolli, P.: Variations in multiscale curvature distribution and signatures of LiDAR DTM errors, Earth Surf. Proc. Land., 38, 1116-1134, doi:10.1002/esp.3363, 2013.

Sofia, G., Marinello, F., and Tarolli, P.: A new landscape metric for the identification of terraced sites: The Slope Local Length of Auto-Correlation (SLLAC), ISPRS J. Photogramm., 96, 123133. doi:10.1016/j.isprsjprs.2014.06.018, 2014.

Sofia, G., Tarolli, P., Cazorzi, F., and Dalla Fontana, G.: Downstream hydraulic geometry relationships: Gathering reference reach-scale width values from LiDAR, Geomorphology, 250, 236-248, doi:10.1016/j.geomorph.2015.09.002, 2015.

Swain, C. J. and Kirby, J. F.: The effect of "noise" on estimates of the elastic thickness of the continental lithosphere by the coherence method, Geophys. Res. Lett., 30, 1574, 2003.

Sweeny, K. E., Roering, J. J., and Ellis. C.: Experimental evidence for hillslope control of landscape scale, Science, 349, 51-53, 2015.

Tarolli, P. and Dalla Fontana, G.: Hillslope-to-valley transition morphology: New opportunities from high resolution DTMs, Geomorphology, 113, 47-56, 2009.

Tarolli, P. and Tarboton, D. G.: A new method for determination of most likely landslide initiation points and the evaluation of digital terrain model scale in terrain stability mapping, Hydrol. Earth Syst. Sci., 10, 663-677, doi:10.5194/hess-10-663-2006, 2006.

Tarolli, P., Sofia, G., Calligaro, S., Prosdocimi, M., Preti, F., and Dalla Fontana, G.: Vineyards in terraced landscapes: New opportunities from LIDAR data, Land Degrad. Dev., 26, 92-102, 2015.

Tate N. J.: Estimating the fractal dimension of synthetic topographic surfaces, Comput. Geosci., 24, 325-334, 1998a.

Tate, N. J.: Maximum entropy spectral analysis for the estimation of fractals in topography, Earth Surf. Proc. Land., 23, 1197-1217, 1998b.

Tomkin, J. H.: Numerically simulating alpine landscapes: The geomorphological consequences of incorporating glacial erosion in surface process models, Geomorphology, 103, 180-188, 2009.

Tseng, C.-M., Lin, C.-W., Dalla Fontana, G., and Tarolli, P.: The topographic signature of a major typhoon, Earth Surf. Proc. Land., 40, 1129-1136, doi:10.1002/esp.3708, 2015.

Tucker, G. and Hancock, G. R.: Modelling landscape evolution, Earth Surf. Proc. Land., 35, 28-50, 2010.

Tucker, G. E., Lancaster, S. T., Gasparini, N., and Bras, R. L.: The channel-hillslope integrated landscape development (child) model, in: Landscape Erosion and Evolution Modeling, edited by: Harmon, R. and Doe, W., Kluwer Academic/Plenum Publishers, New York, USA, 349-388, 2001. van der Mark, C. F., Blom, A., and Hulscher S. J. M. H.: Quantification of variability in bedform geometry, J. Geophys. Res., 113, F03020, doi:10.1029/2007JF000940, 2008.

Venditti, J. G.: Bedforms in sand-bedded rivers, in: Treatise on Geomorphology, edited by: Shroder Jr., J. and Wohl, E., Academic Press, San Diego, CA, USA, 9, 137-162, 2012.

Wechsler S. P. and Kroll C.: Quantifying DEM uncertainty and its effect on topographic parameters, Photogramm. Eng. Rem. S., 72, 1081-1090, 2006.

Weissel, J. K., Pratson, L. F., and Malinverno, A.: The lengthscaling properties of topography, J. Geophys. Res. 99, 13997 14012, 1994. Wessel, P.: Sizes and ages of seamounts using remote sensing: implications for intraplate volcanism, Science, 80 , 802-805, 1997.

Wessel, P.: An Empirical Method for Optimal Robust RegionalResidual Separation of Geophysical Data, Math. Geol., 30, 391408, 1998.

Wessel, P.: Global Distribution of Seamounts Inferred from Gridded Geosat/ERS-1 Altimetry, J. Geophys. Res., 106, 19431-19441, 2001.

Wessel, P. and Smith, W. H. F.: New, improved version of Generic Mapping Tools released, Eos Trans. Am. Geophys. Union, 79, $579,1998$.

Willgoose, G.: A physical explanation for an observed area-slopeelevation relationship for catchments with declining relief, Water Resour. Res., 30, 151-159, doi:10.1029/93WR01810, 1994.

Willgoose, G. R., Bras, R. L., and Rodriguez-Iturbe, I.: A physically based coupled network growth and hillslope evolution model, 1, theory, Water Res. Res., 27, 1671-1684, 1991.

Wohl, E.: Limits of downstream hydraulic geometry, Geol., 32, 897-900, doi:10.1130/G20738.1, 2004.

Wren, E. A.: Trend Surface Analysis - A review, Canadian Journal of Exploration Geophysics, 9, 39-45, 1973.

Zhang, D., Narteau, C., and Rozier, O.: Morphodynamics of barchan and transverse dunes using a cellular automaton model, J. Geophys. Res., 115, F03041, 2010.

Zhou, Q. and Liu, X.: Error assessment of grid-based flow routing algorithms used in hydrological models, Int. J. Geogr. Inf. Sci., 16, 819-842. doi:10.1080/13658810210149425, 2002.

Zhou, Q. and Liu, X.: Assessing Uncertainties in Derived Slope and Aspect from a Grid DEM, in: Advances in Digital Terrain Analysis SE - 15, Lecture Notes in Geoinformation and Cartography, edited by: Zhou, Q., Lees, B., and Tang, G., Springer, Berlin Heidelberg, Germany, 279-306. doi:10.1007/978-3-540-778004_15, 2008.

Zhou, Q. M. and Liu, X. J.: Analysis of errors of derived slope an aspect related to DEM data properties, Comput. Geosci, 30, 369378, 2004. 